\title{
THERMOPHORESIS EFFECT ON THE FREE CONVECTIVE FLOW IN A DIFFERENTIALLY HEATED SQUARE CAVITY
}

\author{
Serban R. POP ${ }^{\mathrm{a}}$, Teodor GROSAN ${ }^{\mathrm{b}^{*}}$ \\ ${ }^{a}$ Faculty of Science and Engineering, Computer Science, University of Chester, Chester, \\ United Kingdom \\ ${ }^{\mathrm{b}}$ Faculty of Mathematics and Computer Science, Babeş-Bolyai University \\ 400084 Cluj-Napoca, Romania \\ * Associate Professor, E-mail: tgrosan@math.ubbcluj.ro
}

\begin{abstract}
A numerical analysis is made for thermophoretic transport of small particles through the convective in a differentially heated square cavity. The governing gas-particle partial differential equations are solved numerically for some values of the considered parameters to investigate their influence on the flow, heat and mass transfer patterns. It is found that the effect of thermophoresis can be quite significant in appropriate situations.
\end{abstract}

Key words: Thermophoretic deposition, Free convection, Newtonian fluid, Differentially heated, Square cavity

\section{Introduction}

The effect known as thermophoresis, whereas a temperature gradient induces an opposite movement to low-sized gas suspended particles, has been studied considerable in the past and has many industrial applications such as: air-cleaning devices to remove submicron- and micron-sized particles from gas streams, deposition of particulate material on heat exchanger surfaces (Epstain et al. [1]), problems including nuclear reactor safety (Tsai and Liang [2]), modified chemical vapour deposition (Jenson et al. [3]), in the semiconductor industry (Opiolka et al. [4]), optical fiber fabrication (Song and Hwang [5]), etc. In the presence of a temperature gradient, in addition to other forces like drag, gravity or Brownian, a thermophoretic force depending on Knudsen number $\left(K n=2 \lambda / d_{p}\right.$, where $d_{p}$ is the particle diameter and $\lambda$ is the gas mean free path) act on the aerosol particles. Reviews of theory and experiments done in the field can be found in Bakarov [6], He and Ahmadi [7], and Piazza and Parola [8].

Thermophoretic aerosol particles deposition in the boundary layer flow of a Newtonian fluid has been extensively studied. Epstein et al. [1] have studied the thermophoretic deposition in a natural convection boundary layer on a cold vertical plate, Goren [9] 
investigated the thermophoretic deposition in a laminar compressible boundary layer flow past a flat plate, etc. They found that the particle concentration at the wall has very close values in both laminar and turbulent flow and that particles are attracted by a plate colder than the gas and the concentration drops monotonically as the wall is approached The thermophoretic aerosol particles deposition in a fluid-saturated porous media was studied by Chamkha and Pop [10] for a vertical flat plate and Postelnicu [11] for a horizontal flat plate. They reported a high deposition of particles on the plate which increases when the thermophoresis parameter increases.

With many industrial and environmental applications, the natural convection of enclosed fluids has been an important subject due to its particular transition to turbulence mechanism by destabilizing the buoyancy-driven flow and its high numerical computational requirements. A large section of the previous research done on this topic has been reviewed by Bejan [12]. Extensive work was done by De Vahl Davis [13] who presented the final form of the problem and computational results for high Rayleigh numbers. The complexity of the system is increased when the convective is not only driven by temperature but concentration differences also. Beghein et al. [14] investigated numerically the thermosolutal natural convection in a square cavity filled with air mixed with different kinds of pollutants subject to horizontal temperature and concentration gradients. The results showed a significant influence of solutal buoyancy force and Lewis number on heat and mass transfer rate at high values of Rayleigh numbers.

In general, the main assumption of the studies which considered the free and mixed convection flow in vertical channels is that the thermophoretic deposition of aerosol particles is negligible. However, due to its fundamental and technological importance, theoretical studies of the thermophoretic effects on particle deposition in channel, tube or pipe flow were performed by many investigators (Weinberg [15], Fiebig et al. [16], Grosan et al. [17] and Chang et al. [18]). Moreover, Chein and Liao [19] presented a numerical model including both the particle molecular diffusion and thermophoretic effects to study nanoparticle deposition in a two-dimensional channel flow subject to two types of thermal conditions. Many practical and industrial applications of the thermophoretic effects can be found in the open literature, for example, a method for hybridization and binding between biomolecules involving thermophoresis, the thermophoretic filtering of liquids and the process for preparation of ceramic film are mentioned in the patents [23], [24] and [25].

However, to the authors' best knowledge, the thermophoretic transport effects in the steady convective flow in square cavity has not been studied before and it is the main aim of this 
paper to study this problem. Flow, concentration and heat transfer results for a range of values of the governing parameters have been reported.

\section{Mathematical model}

We consider the natural convection of a warm gas, containing suspended aerosol particles, confined in a rectangular cavity. The coordinate system is chosen such that the origin is set in the cavity's bottom left corner and the $y$-axis is parallel and of opposite direction with the gravitational acceleration vector $g$. In this paper the cavity is considered to be square hence the height is denoted by $L$ (see Figure 1). The left hand wall is at given uniform temperature $T_{h}$ and concentration $C_{h}$, while the right hand one is subjected to a uniform temperature $T_{c}$ and concentration $C_{c}$, where $T_{h}>T_{c}$ and $C_{h}>C_{c}$. Considering all the fluid properties except density in the buoyancy term (Boussinesq approximation) the governing equations written in Cartesian coordinates $x, y$ are given by

$$
\begin{gathered}
\frac{\partial u}{\partial x}+\frac{\partial v}{\partial y}=0 \\
u \frac{\partial u}{\partial x}+v \frac{\partial u}{\partial y}=-\frac{1}{\rho} \frac{\partial p}{\partial x}+v\left(\frac{\partial^{2} u}{\partial x^{2}}+\frac{\partial^{2} u}{\partial y^{2}}\right) \\
u \frac{\partial v}{\partial x}+v \frac{\partial v}{\partial y}=-\frac{1}{\rho} \frac{\partial p}{\partial y}+v\left(\frac{\partial^{2} v}{\partial x^{2}}+\frac{\partial^{2} v}{\partial y^{2}}\right)+\left[\beta_{T}\left(T-T_{0}\right)+\beta_{C}\left(C-C_{0}\right)\right] g \\
u \frac{\partial T}{\partial x}+v \frac{\partial T}{\partial y}=\alpha\left(\frac{\partial^{2} T}{\partial x^{2}}+\frac{\partial^{2} T}{\partial y^{2}}\right) \\
u \frac{\partial C}{\partial x}+v \frac{\partial C}{\partial y}+\frac{\partial}{\partial x}\left(u_{T} C\right)+\frac{\partial}{\partial y}\left(v_{T} C\right)=D\left(\frac{\partial^{2} C}{\partial x^{2}}+\frac{\partial^{2} C}{\partial y^{2}}\right)
\end{gathered}
$$

The boundary conditions of these equations are

$$
\begin{array}{ll}
x=0: & u=v=0, \quad T=T_{h}, \quad C=C_{h} \\
x=L: & u=v=0, \quad T=T_{c}, \quad C=C_{c} \\
y=0: & u=v=0, \quad \frac{\partial T}{\partial y}=\frac{\partial C}{\partial y}=0 \\
y=L: & u=v=0, \quad \frac{\partial T}{\partial y}=\frac{\partial C}{\partial y}=0
\end{array}
$$

Here $u$ and $v$ are the two dimensional fluid velocity components, $p$ is the dynamic pressure, which is equal to the total pressure minus the hydrostatic component, $T$ is the fluid temperature, $C$ is the particle concentration, and $u_{T}$ and $v_{T}$ are the thermophoretic 
deposition velocity components, which are defined as

$$
u_{T}=-k_{T} \frac{v}{T} \frac{\partial T}{\partial x}, \quad v_{T}=-k_{T} \frac{v}{T} \frac{\partial T}{\partial y}
$$

The dimensionless coefficient $k_{T}$ depends on the Knudsen number $K n$ and the ratio of the thermal conductivity between the gas and particles. According to Talbot et al. [20], $k_{T}$ is expressed as

$$
k_{T}=\frac{2 C_{s} C_{C}\left\lfloor\left(k_{f} / k_{p}\right)+C_{t} K_{n}\right\rfloor}{\left(1+3 C_{m} K_{n}\right)\left(1+2 k_{f} / k_{p}+2 C_{t} K_{n}\right)}
$$

The values of $C_{t}, C_{m}, C_{s}$ are $2.18,1.14,1.17$ and the values of $k_{T}$ is in the range $0.2 \leq k_{T} \leq 1.2$ (Batchelor and Shen [21]). The physical meaning of the other quantities is described in the Nomenclature. Further, it is assumed that particles have only one size, hence the particulate matter is diluted enough that pairs or groups of particles may be considered (Epstein et al. [1]).

Further, we introduce the following non-dimensional variables

$$
\begin{aligned}
& X=x / L, \quad Y=y / L, \quad U=u / U_{0}, V=v / U_{0}, \theta=\left(T-T_{0}\right) /\left(T_{h}-T_{c}\right), \\
& \phi=\left(C-C_{0}\right) /\left(C_{h}-C_{c}\right), P=\left(\mu U_{0} / L\right) p, U_{T}=(\rho L / \mu) u_{T}, \quad V_{T}=(\rho L / \mu) v_{T}
\end{aligned}
$$

where $U_{0}$ is defined as $U_{0}=\alpha / L$ and $T_{0}$ and $C_{0}$ are the characteristic temperature and concentration given by $T_{0}=\left(T_{h}+T_{c}\right) / 2$ and $C_{0}=\left(C_{h}+C_{c}\right) / 2$.Using the dimensionless stream function $\psi$ and vorticity function $\Omega$, which are defined as usual $U=\partial \psi / \partial Y, \quad V=-\partial \psi / \partial X$ and $\Omega=-\left(\partial^{2} \psi / \partial X^{2}+\partial^{2} \psi / \partial Y^{2}\right)$, we obtain the following dimensionless system of equations:

$$
\begin{gathered}
\frac{\partial \Omega}{\partial X} \frac{\partial \psi}{\partial Y}-\frac{\partial \psi}{\partial X} \frac{\partial \Omega}{\partial Y}=\operatorname{Pr}\left(\frac{\partial^{2} \Omega}{\partial X^{2}}+\frac{\partial^{2} \Omega}{\partial Y^{2}}\right)-\operatorname{Ra} \operatorname{Pr}\left(\frac{\partial \theta}{\partial X}+\beta \frac{\partial \phi}{\partial X}\right) \\
\frac{\partial \theta}{\partial X} \frac{\partial \psi}{\partial Y}-\frac{\partial \psi}{\partial X} \frac{\partial \theta}{\partial Y}=\frac{\partial^{2} \theta}{\partial X^{2}}+\frac{\partial^{2} \theta}{\partial Y^{2}} \\
\frac{\partial \phi}{\partial X} \frac{\partial \psi}{\partial Y}-\frac{\partial \psi}{\partial X} \frac{\partial \phi}{\partial Y}=\frac{\operatorname{Pr}}{S c}\left(\frac{\partial^{2} \phi}{\partial X^{2}}+\frac{\partial^{2} \phi}{\partial Y^{2}}\right) \\
+\operatorname{Pr}\left\{\frac{\partial}{\partial X}\left[\frac{k_{T}}{N_{T}+\theta} \frac{\partial \theta}{\partial X}\left(\phi+N_{C}\right)\right]+\frac{\partial}{\partial Y}\left[\frac{k_{T}}{N_{T}+\theta} \frac{\partial \theta}{\partial Y}\left(\phi+N_{C}\right)\right]\right\}
\end{gathered}
$$

and the boundary conditions (6) become 


$$
\begin{array}{ll}
X=0: \quad \psi=\Omega=0, \quad \theta=1 / 2, \quad \phi=1 / 2 \\
X=1: \quad \psi=\Omega=0, \quad \theta=-1 / 2, \quad \phi=-1 / 2 \\
Y=0: \quad \psi=\Omega=0, \quad \frac{\partial \theta}{\partial y}=\frac{\partial \phi}{\partial y}=0 \\
Y=1: \quad \psi=\Omega=0, \quad \frac{\partial \theta}{\partial y}=\frac{\partial \phi}{\partial y}=0
\end{array}
$$

Here the parameters $\operatorname{Ra}, \operatorname{Pr}, S c, \beta, N_{T}$ and $N_{C}$ are defined as

$$
\begin{gathered}
R a=\frac{g \beta_{T}\left(T_{h}-T_{c}\right) L^{3}}{\alpha v}, \quad \operatorname{Pr}=\frac{v}{\alpha}, \quad S c=\frac{v}{D}, \quad \beta=\frac{\beta_{C}\left(C_{h}-C_{c}\right)}{\beta_{T}\left(T_{h}-T_{c}\right)}, \\
N_{T}=\frac{T_{h}+T_{c}}{2\left(T_{h}-T_{c}\right)}, \quad N_{C}=\frac{C_{h}+C_{c}}{2\left(C_{h}-C_{c}\right)}
\end{gathered}
$$

It is to be noticed that when $\beta=0$, there is no mass transfer and the buoyancy force is due to thermal diffusion only. The mass transfer driven flow is valid for both positive and negative values of $\beta$. Hence, the two buoyant mechanisms aid each other when $\beta>0$ and oppose each other when $\beta<0$, respectively (Mahajan and Angirasa [22]).

The physical quantities of interest the mean Nusselt number $N u$ and the mean Sherwood number $S h$ given by

$$
N u=-\int_{0}^{1}\left(\frac{\partial \theta}{\partial x}\right)_{x=0} d y, S h=-\int_{0}^{1}\left(\frac{\partial \phi}{\partial x}\right)_{x=0} d y
$$

\section{Numerical method}

The numerical solution of system (10)-(13) was obtained using a central finite-difference scheme together with a Gauss-Seidel iteration technique. The unknowns $\theta, \phi, \psi$ and $\Omega$ were iteratively computed until the following convergence criteria was fulfilled $\mid \max \left[f_{\text {new }}(i, j)-f_{\text {old }}(i, j)\right]<\varepsilon$, where $f$ represents the temperature, concentration, stream function or vorticity and $\varepsilon(=10 \mathrm{e}-7)$ is the convergence criteria.

Table 1. Grid dependence study for $R a=1000, \operatorname{Pr}=1, S c=1, k_{T}=1$ and $\beta=1$.

\begin{tabular}{|ccc|}
\hline Nodes & $N u$ & $S h$ \\
\hline $26 \times 26$ & 1.33867 & 1.31954 \\
$51 \times 51$ & 1.33047 & 1.31151 \\
$101 \times 101$ & 1.32649 & 1.30759 \\
$201 \times 201$ & 1.32454 & 1.30568 \\
$301 \times 301$ & 1.32382 & 1.30498 \\
\hline
\end{tabular}


In all presented results the value was found to be sufficiently small such that any other smaller value produced results graphically similar. In order to determine the proper mesh size we performed accuracy tests for mesh sensitivity using the scheme described above with the following parameters $R a=1000, \operatorname{Pr}=1, S c=1, k_{T}=1$ and $\beta=1$. This table clearly shows a good agreement for the mesh size 201x201 which was later on used in all our computations. Comparison results of other published papers (see De Vahl Davis [13] and Beghein et al. [14] ) are shown in Table 2 when thermophoresis is absent. It is seen that the present results are in very good agreement with those determined in the papers mentioned above. Therefore we are confident that the present results are accurate.

Table 2. Validation of the code for $N u$ and $S h$ when $\mathrm{Pr}=0.71$ in the absence of thermophoresis $\left(k_{T}=0\right)$.

\begin{tabular}{|c|c|c|c|c|c|c|c|c|}
\hline \multirow{2}{*}{$R a$} & \multirow{2}{*}{$S c$} & \multirow{2}{*}{$\beta$} & \multicolumn{2}{|c|}{ De Vahl Davis [13] } & \multicolumn{2}{c|}{ Beghein et al. [14] } & \multicolumn{2}{c|}{ Present results } \\
\cline { 4 - 9 } & & & $N u$ & $S h$ & $N u$ & $S h$ & $N u$ & $S h$ \\
\hline 1000 & 0 & 0 & 1.118 & & & & 1.11852 & \\
\hline 10000 & 0.71 & 1 & & & 2.7719 & 2.7719 & 2.77378 & 2.77378 \\
\hline
\end{tabular}

Table 3. Values of $N u$ and $S h$ for $R a=1000$ and several values of the parameters $S c, \beta$ and $k_{T}$.

\begin{tabular}{|c|c|c|c|c|c|c|c|c|c|}
\hline Sc & $\beta$ & $k_{T}$ & $\mathrm{Nu}$ & $S h$ & $S c$ & $\beta$ & $k_{T}$ & $\mathrm{Nu}$ & $S h$ \\
\hline \multirow[t]{12}{*}{0.1} & \multirow[t]{3}{*}{0} & 0.1 & 1.11863 & 1.00047 & \multirow[t]{12}{*}{10} & \multirow[t]{3}{*}{0} & 0.1 & 1.11863 & 2.65589 \\
\hline & & 0.5 & 1.11864 & 0.99893 & & & 0.5 & 1.11864 & 2.29198 \\
\hline & & 1.0 & 1.11864 & 0.9951 & & & 1.0 & 1.11864 & 1.871 \\
\hline & \multirow[t]{3}{*}{0.1} & 0.1 & 1.14083 & 1.00059 & & \multirow[t]{3}{*}{0.1} & 0.1 & 1.12488 & 2.71894 \\
\hline & & 0.5 & 1.14089 & 0.997706 & & & 0.5 & 1.12659 & 2.34539 \\
\hline & & 1.0 & 1.14092 & 0.993304 & & & 1.0 & 1.12867 & 1.88759 \\
\hline & \multirow[t]{3}{*}{1} & 0.1 & 1.36628 & 1.00319 & & \multirow[t]{3}{*}{1} & 0.1 & 1.16341 & 3.07748 \\
\hline & & 0.5 & 1.3668 & 0.996827 & & & 0.5 & 1.18109 & 2.68258 \\
\hline & & 1.0 & 1.36745 & 0.988767 & & & 1.0 & 1.20464 & 2.18702 \\
\hline & \multirow[t]{3}{*}{5} & 0.1 & 2.22784 & 1.03581 & & \multirow[t]{3}{*}{5} & 0.1 & 1.23911 & 4.07485 \\
\hline & & 0.5 & 2.23151 & 1.01906 & & & 0.5 & 1.34416 & 3.58728 \\
\hline & & 1.0 & 2.2361 & 0.997977 & & & 1.0 & 1.47757 & 2.96593 \\
\hline \multirow[t]{7}{*}{1} & \multirow[t]{3}{*}{0} & 0.1 & 1.11863 & 1.11349 & \multirow[t]{7}{*}{100} & \multirow[t]{3}{*}{0} & 0.1 & 1.11863 & 5.63976 \\
\hline & & 0.5 & 1.11864 & 1.10353 & & & 0.5 & 1.11864 & 3.5729 \\
\hline & & 1.0 & 1.11864 & 1.05454 & & & 1.0 & 1.11864 & 1.58549 \\
\hline & \multirow[t]{3}{*}{0.1} & 0.1 & 1.13938 & 1.12801 & & \multirow[t]{3}{*}{0.1} & 0.1 & 1.12065 & 5.74837 \\
\hline & & 0.5 & 1.13971 & 1.08377 & & & 0.5 & 1.12271 & 3.65517 \\
\hline & & 1.0 & 1.14007 & 1.02735 & & & 1.0 & 1.12539 & 1.64997 \\
\hline & 1 & 0.1 & 1.32448 & 1.30558 & & 1 & 0.1 & 1.12816 & 6.22427 \\
\hline
\end{tabular}




\begin{tabular}{|c|c|c|c|c|c|c|c|}
\hline & 0.5 & 1.33042 & 1.23532 & & 0.5 & 1.14873 & 4.06753 \\
\hline & 1.0 & 1.33812 & 1.14580 & & 1.0 & 1.17727 & 1.92986 \\
\hline \multirow[t]{3}{*}{5} & 0.1 & 1.918 & 1.88416 & \multirow[t]{3}{*}{5} & 0.1 & 1.12695 & 7.71002 \\
\hline & 0.5 & 1.94725 & 1.77739 & & 0.5 & 1.24548 & 5.42655 \\
\hline & 1.0 & 1.98275 & 1.64208 & & 1.0 & 1.39827 & 2.7756 \\
\hline
\end{tabular}

\section{Results and discussion}

Equations (10) to (12), subject to the boundary conditions (13), have been solved numerically for the following values of the involved parameters $N_{C}=2, N_{T}=8$, $\beta=0,0.1,1$ and $5, S c=0.1,1,10$ and $100, \operatorname{Pr}=0.71$ and $k_{T}=0.1,0.5$ and 1. Values of the mean Nusselt and Sherwood numbers on the left (hot) wall are given in Table 3 for $R a=1000$ and several values of the parameters $S c, \beta$ and $k_{T}$. It is seen from this table that $N u$ increases when $\beta$ and $k_{T}$ increase and decreases when $S c$ increases while $S h$ increases when $S c$ and $\beta$ increase and decreases when $k_{T}$ increases. The increase of $\beta$ leads to an enhancement of the concentration in the buoyancy term (Eq. (10)), while the increase of $k_{T}$ determines an augmentation of the thermophoretic effect (Eq. (12)) and therefore $N u$ increases. On the other side, the increasing of $S c$ diminishes the mass diffusion determining the decreasing of $N u$. The drop of $S h$ with $k_{T}$ is due to the thermophoretic effect causing migration of the particles from the hot to the cold wall, while the growth of $S h$ with $S c$ and $\beta$ is due to the decline of mass diffusion and to the enhancement of buoyancy. 


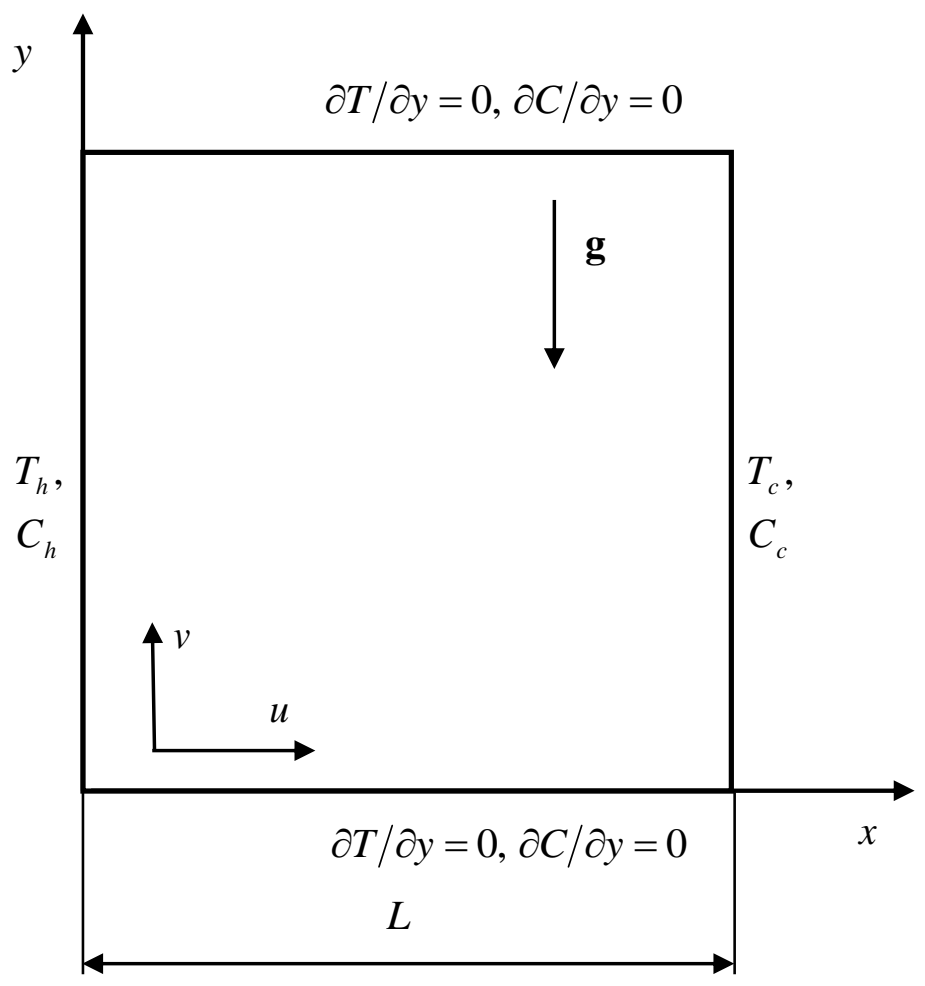

Fig. 1. Physical model and coordinate system.

Figures 2 to 4 display the main characteristic of the flow pattern: streamlines, isotherms and isoconcentrations for $R a=1000, k_{T}=1, S c=1,10$ and 100 and $\beta=0.1,1$ and 5. The increase of Schmidt number $S c$ determinates a decrease in the maximum value of the stream function and a small change in isotherms where a stratification near the vertical wall is present for large values of $S c$. Instead, the influence of $S c$ on isoconcentrations is more pregnant. For large values of $S c$ the concentration field changes and the diffusion "plumes" are present near the vertical wall (see Fig 3 and Fig4.). The "plumes" orientation are downward near the left (hot) wall and upward near the right (cold) wall.
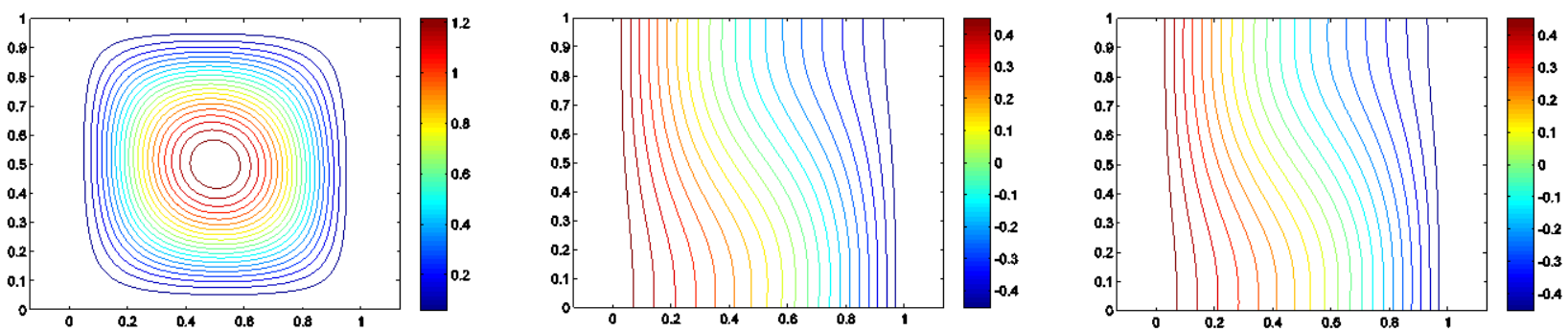

a) 

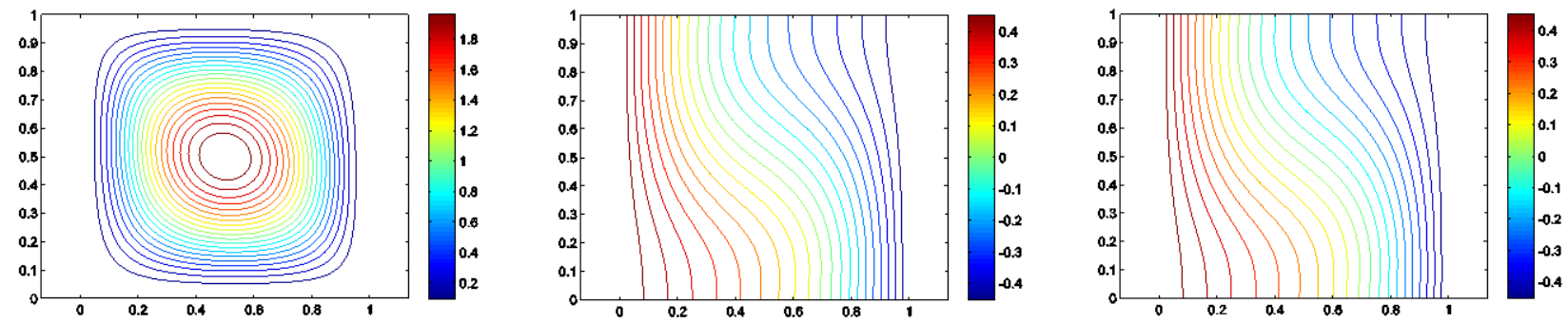

b)
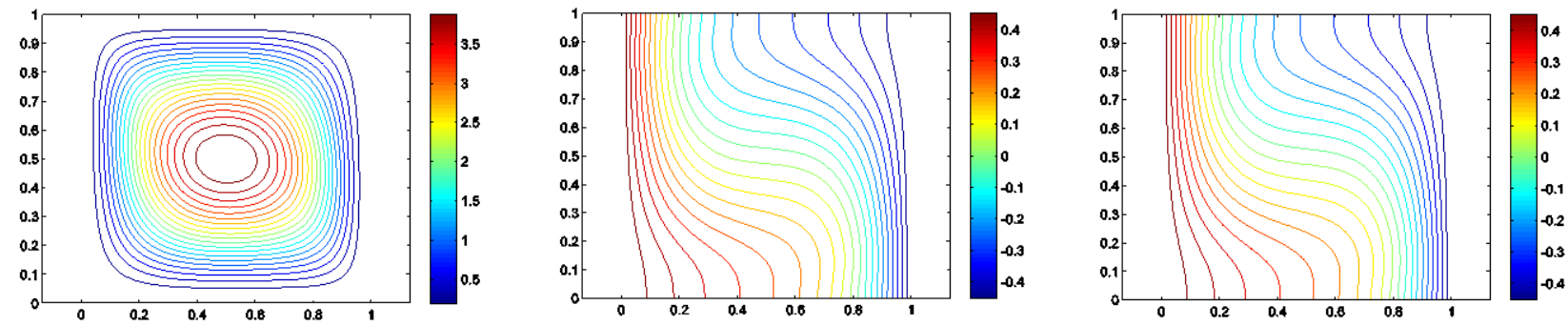

c)

Fig. 2. Streamlines, isotherms and isoconcentrations for $R a=1000, k_{T}=1, S c=1$ and a) $\beta=0.1$, b) $\beta=1$ and c) $\beta=5$

On the other hand, the effect of the bouyancy ratio parameter $\beta$ is more present for small values of the Schmidt number $S c$. Thus, for $S c=1$ the maximum value of the stream function increases almost three times and this leads to a distortion of the isotherms and concentration lines in the flow direction (see Fig. 2). It can be seen in Fig. 3.that for $S c=10$ a stratification of the flow is present for large values of $\beta$ and this phenomenon modify the isoconcentration pattern (see Fig. 3c). It is worth to mention that for large values of $S c$ a boundary layer is formed near the vertical walls and this in combination with the concentration "plume - like" distribution determines a distortion of the streamlines along the second diagonal of the cavity.
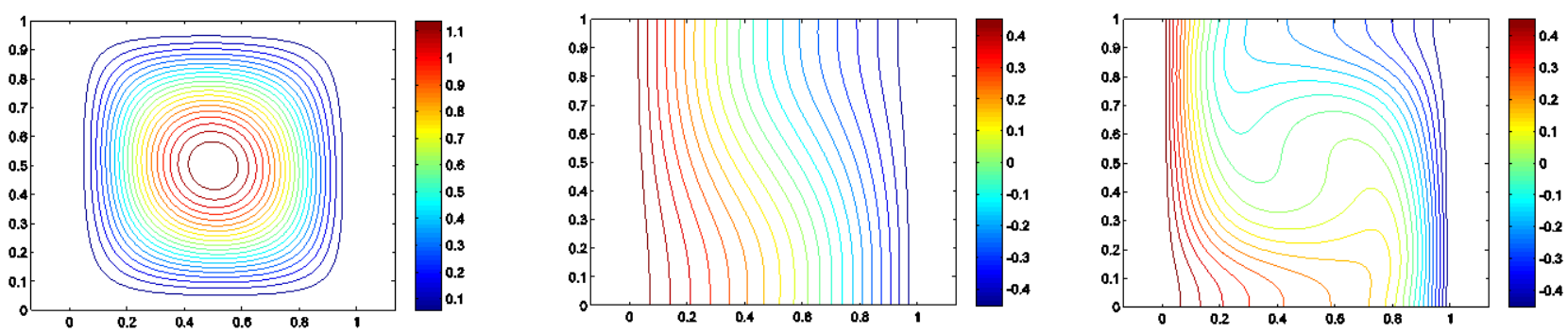

a) 

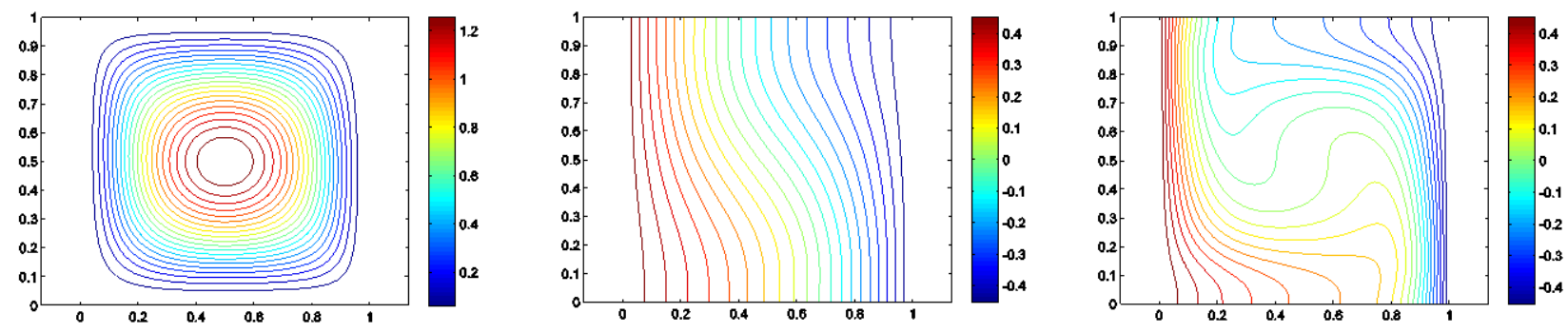

b)
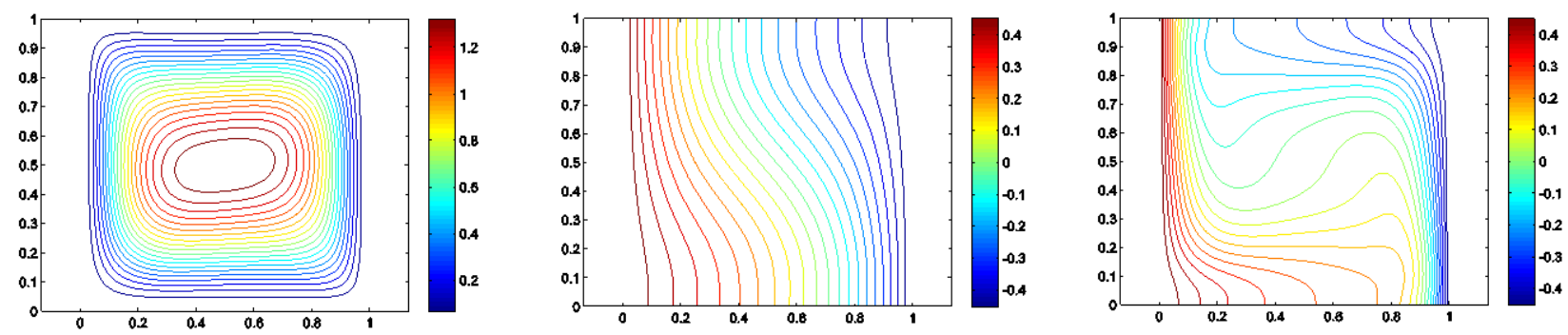

c)

Fig. 3. Streamlines, isotherms and isoconcentrations for $R a=1000, k_{T}=1, S c=10$ and a) $\beta=0.1$, b) $\beta=1$ and c) $\beta=5$
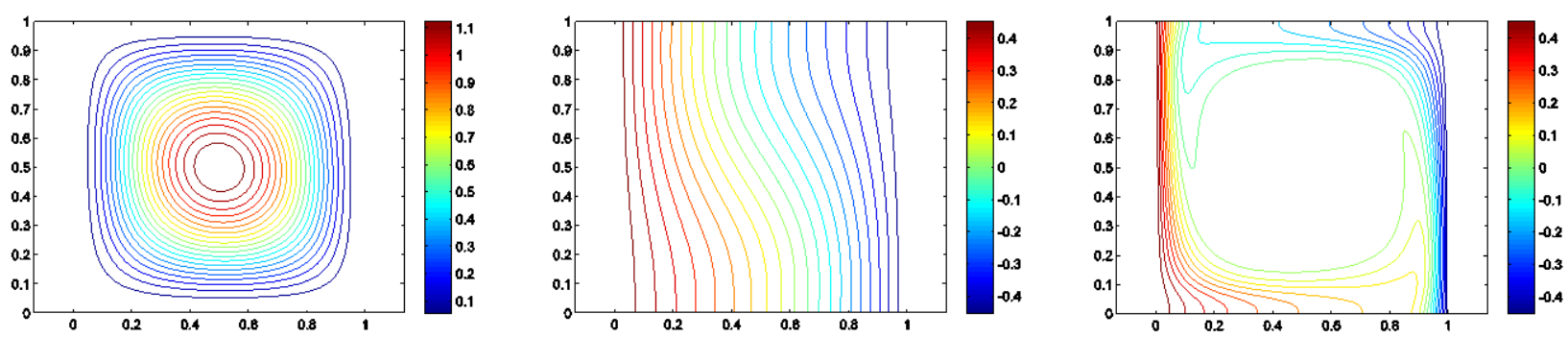

a)
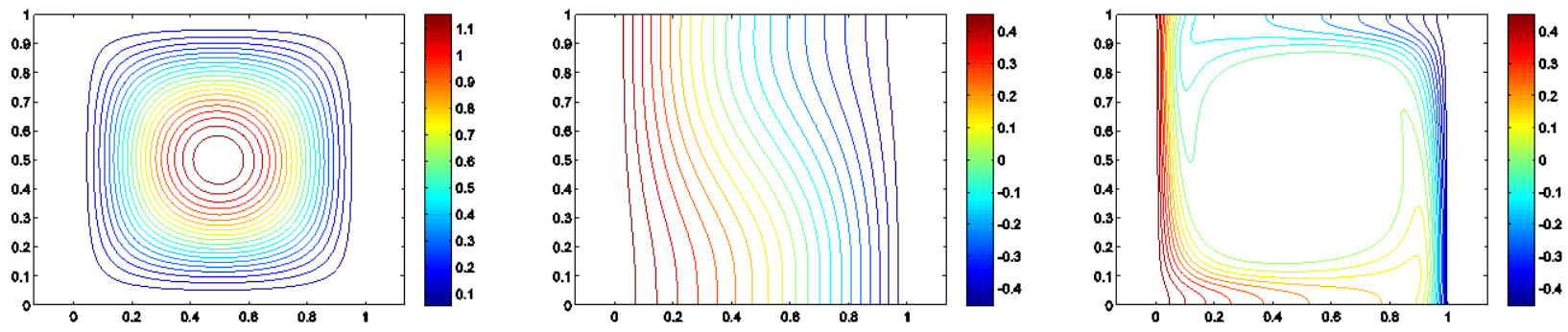

b) 

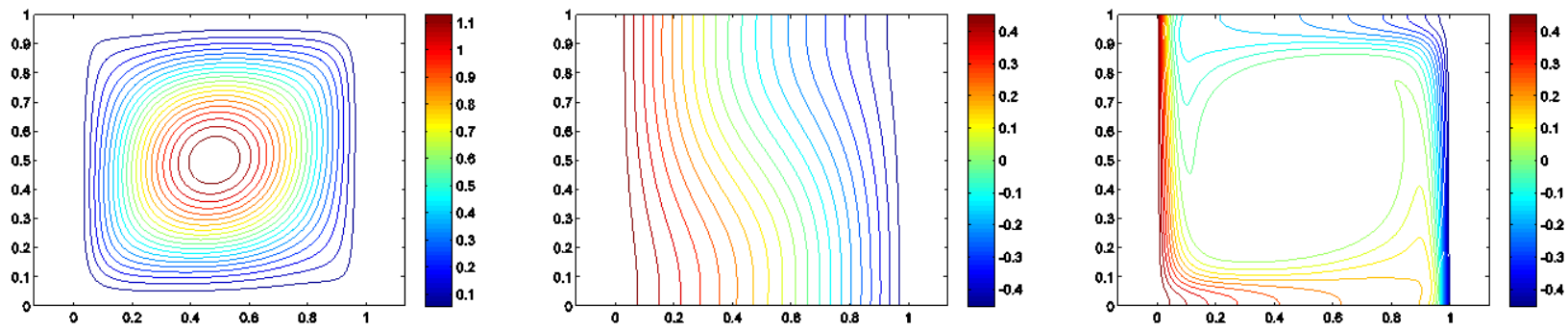

c)

Fig. 4. Streamlines, isotherms and isoconcentrations for $R a=1000, k_{T}=1, S c=100$ and a) $\beta=0.1$, b) $\beta=1$ and c) $\beta=5$

\section{Acknowledgments}

This work was supported by a grant of the Romanian National Authority for Scientific Research, CNCS - UEFISCDI, Project Number PN-II-RU-TE-2011-3-0013.

\section{Nomenclature}

$C \quad$ particle concentration, $\left[\mathrm{kg} \mathrm{m}^{-3}\right]$

$C_{0} \quad$ characteristic concentration, $\left[\mathrm{kg} \mathrm{m}^{-3}\right]$

$C_{c} \quad$ concentration of the right wall, $\left[\mathrm{kg} \mathrm{m}^{-3}\right]$

$C_{C} \quad$ Cunningham correction factor, [-]

$C_{h} \quad$ concentration of the left wall, $\left[\mathrm{kg} \mathrm{m}^{-3}\right]$

$C_{m} \quad$ velocity jump coefficient, [-]

$C_{p} \quad$ specific heat at constant pressure, [ $\mathrm{J} \mathrm{kg}^{-1} \mathrm{~K}^{-1}$ ]

$C_{s} \quad$ temperature creeping coefficient, [-]

$C_{t} \quad$ temperature jump coefficient, [-]

$D$ diffusion coefficient, $\left[\mathrm{m}^{2} \mathrm{~s}^{-1}\right]$

$d_{p} \quad$ nanoparticle diameter, [m]

$g \quad$ acceleration due to gravity, $\left[\mathrm{m} \mathrm{s}^{-2}\right]$

$k_{f} \quad$ thermal conductivity of the fluid, [W m $\mathrm{m}^{-1} \mathrm{~K}^{-1}$ ]

$k_{p} \quad$ thermal conductivity of the particles, [W m-1 $\mathrm{K}^{-1}$ ]

$K n \quad$ Knudsen number, [-]

$k_{T} \quad$ dimensionless thermophoretic coefficient, [-]

$L \quad$ height of the cavity, [m]

$\mathrm{Nu} \quad$ Nusselt number, [-]

\section{Greek symbols}

$\alpha \quad$ thermal diffusivity, $\left[\mathrm{m}^{2} \mathrm{~s}^{-1}\right]$
$N_{T}, N_{C}$ termophoresis parameters, [-]

$p \quad$ dimensional dynamic pressure, $\left[\mathrm{kg} \mathrm{m}^{-1} \mathrm{~s}^{-2}\right]$

$P \quad$ dimensionless dynamic pressure, [-]

Pr Prandtl number, [-]

$R a \quad$ modified Rayleigh number, [-]

$R e \quad$ Reynolds number, [-]

Sc Schmidt number, [-]

Sh Sherwood number, [-]

$T \quad$ fluid temperature, [K]

$T_{0} \quad$ characteristic temperature, [K]

$T_{c} \quad$ temperature of the right wall, [K]

$T_{h} \quad$ Temperature of the left wall, [K]

$x, y \quad$ dimensional Cartesian coordinates, [m]

$X, Y$ dimensionless Cartesian coordinates, [-]

$u, v \quad$ dimensional velocity components $\left[\mathrm{m} \mathrm{s}^{-1}\right]$

$U, V$ dimensionless velocity components, [-]

$U_{0} \quad$ characteristic velocity, $\left[\mathrm{m} \mathrm{s}^{-1}\right]$

$u_{T}, v_{T}$ dimensional thermophoretic velocity components, $\left[\mathrm{m} \mathrm{s}^{-1}\right]$

$U_{T}, V_{T}$ dimensionless thermophoretic velocity components, [-]

$\beta \quad$ buoyancy ratio parameter, [-] 


$\begin{array}{llll}\beta_{T} & \text { coefficient of thermal expansion, }\left[\mathrm{K}^{-1}\right] & \mu & \text { dynamic viscosity, }\left[\mathrm{N} \mathrm{s} \mathrm{m}{ }^{-2}\right] \\ \beta_{C} & \text { coefficient of concentration expansion, } & v & \text { kinematic viscosity, }\left[\mathrm{m}^{2} \mathrm{~s}^{-1}\right] \\ & {\left[\mathrm{m}^{-1} \mathrm{~kg}^{3}\right]} & \theta & \text { dimensionless temperature, [-] } \\ \varepsilon & \text { numerical tolerance, [-] } & \rho & \left.\text { density, [kg m } \mathrm{kg}^{-3}\right] \\ \phi & \text { dimensionless particle concentration, [-] } & \Omega & \text { dimensionless vorticity, [-] } \\ \lambda & & \psi & \text { dimensionless streamline function, [-] }\end{array}$

\section{References}

[1] Epstein, M., et al., Thermophoretic Deposition of Particles in Natural Convection Flow from a Vertical Plate, ASME J. Heat Transfer 107 (1985), pp. 272-276

[2] Tsai, R., Liang, L.J., Correlation for Thermophoretic Deposition of Aerosol Particles onto Cold Plates, Aerosol Science 32 (2001), pp. 473-487

[3] Jenson, F. J., et al., Flow Phenomena in Chemical Vapour Deposition of Thin Film, Ann. Rev. Fluid Mech. 23 (1991), pp. 197-232

[4] Opiolka, S., et al., Combined Effect of Electrophoresis and Thermophoresis on Particle Deposition onto Flat Surfaces, J. Aerosol Sci. 25 (1994), pp. 665-671

[5] Song, C.G., Hwang, J., Particle Deposition on a Rotating Disk in Application to Vapour Axial Deposition (VAD) Process, J. Aerosol Sci. 29 (1988) pp. 99-114

[6] Bakarov, S.P., Thermophoresis in Gas at Small Knudsen Numbers, Aerosol Sci. Technol. 15 (1991), pp. 77-92

[7] He, C., Ahmadi, G., Particle Deposition with Thermophoresis in Laminar and Turbulent Duct Flow, Aerosol Sci. Technol. 29 (1998), pp. 525-546

[8] Piazza, R., Parola, A., Thermophoresis in Colloidal Suspensions, Journal of Physics, Condensed Matter 20 (2008), 153102

[9] Goren, S.L., Thermophoresis of Aerosol Particles in the Laminar Boundary Layer on a Flat Plate, J. Colloid Interface Sci. 61 (1977), pp. 77-85

[10] Chamka A., Pop I., Effect of Thermophoresis Particle Deposition in Free Convection Boundary Layer from a Vertical Flat Plate Embedded in a Porous Medium, Int. Comm. Heat Mass Transfer 31 (2004), pp. 421-430

[11] Postelnicu A., Effects of Thermophoresis Particle Deposition in Free Convection Boundary Layer from a Horizontal Flat Plate Embedded in a Porous Medium, Int. J. Heat Mass Transfer 50 (2007), pp. 2981-2985

[12] Bejan A., Convection Heat Transfer, John Wiley \& Sons, New York, 2004.

[13] De Vahl Davis, G., Natural Convection of Air in a Square Cavity. A Benchmark Numerical Solution, Int. J. Num. Methods Fluids 2 (1983), pp. 249-264

[14] Beghein, C., et al., Numerical Study of Double-Diffusive Natural Convection in a Square Cavity, Int. J. Heat Mass Transfer 35 (1992), pp. 833-846

[15] Weinberg, M.C., Thermophoretic Deposition of Particles in Laminar Flow in a Concentric Annulus, J. Amer. Ceram. Soc. 66 (1983), pp. 439-445

[16] Fiebig, N., et al., Modified Chemical Vapour Deposition Process in a Concentric 
Annulus, Aerosol Sci. Technol. 9 (1988), pp. 237-249

[17] Grosan, T., et al., Thermophoretic Deposition of Particles in Fully Developed Mixed Convection Flow in a Parallel-Plate Vertical Channel, Heat Mass Transfer 45 (2009), pp. 503-509

[18] Chang, Y.C., et al., Thermophoresis in the Croyogenic Temperature Range, J. Aeros. Sci. 26 (1995), pp. 407-428

[19] Chein, R., Liao, W., Thermophoretic Effects on Nano-Particle Deposition in Channel Flow, Heat Mass Transfer 42 (2005), pp. 71-79

[20] Talbot L., et al., Thermophoresis of Particles in a Heated Boundary Layer, J. Fluid Mech. 101 (1980), pp. 737-758

[21] Batchelor, G.K., Shen, C., Thermophoretic Deposition in Gas Flow over Cold Surfaces, J. Colloid Interface Sci. 107 (1985), pp. 21-37

[22] Mahajan, R.L., Angirasa, D., Combined Heat and Mass Transfer by Natural Convection with Opposing Buoyancies, ASME J. Heat Transfer 115 (1993), pp. 606612

[23] Sogard, M., Methods and devices for hybridization and binding assays using thermophoresis, Patent US 8852858 B2, 2014.

[24] Batchelder, J.S., et al., Thermophoretic filtering of liquids, Patent US 5158690 A, 1992.

[25] Komiyama, H., Process for preparation of ceramic film, Patent US 4654228 A, 1987. 